\title{
La reforma constitucional de 1860 : la necesidad de reformar la Constitución liberal de 1856
}

\section{The Constitutional Reform of 1860: The Need to Reform the Liberal Constitution of 1856}

\author{
José Carlos Jiyagón Villanueva \\ Universidad de Lima
}

\section{RESUMEN}

El ocaso de la Convención Nacional en 1857 marca un giro político en el gobierno del general Ramón Castilla, que asume una política de exclusión hacia los sectores liberales. Para poder llevar a cabo este cambio, se pone en observación la Constitución de 1856, fruto del liberalismo de la época. Empieza una campaña conservadora para poder implementar la reforma constitucional y se señala, en una serie de escritos, los defectos que tiene dicho documento y la necesidad de su reforma.

\section{Palabras clave:}

Constitución de 1856 / Liberales / Conservadores / Abolición de fueros / Juntas departamentales

\begin{abstract}
The twilight of the National Convention in 1857 marks the political change made by the government of Gen. Ramon Castilla, who assumed a policy of exclusion towards the liberal sectors. In order to carry out this change, the constitution of 1856 (product of the liberalism) was observed. A conservative campaign began to implement a constitutional reform, pointing out a series of errors found in the constitution, which demonstrated the need to reform it.
\end{abstract}

\section{Keywords:}

Constitution of 1856 / Liberal / Conservatives / Abolition of jurisdictions / Departmental meetings
L a revolución liberal de 1854 permitió, por segunda vez, el encumbramiento del general Ramón Castilla en la presidencia, esta vez con el apoyo de una generación de políticos liberales, que deseaban implementar una serie de reformas políticas y sociales. Como fruto de ello, en 1855 se reunió una asamblea legislativa denominada Convención Nacional, que procedió a elaborar una nueva Carta Magna en la que se establecieron los ideales políticos de
Ios sectores liberales. Temas sensibles como la reducción del mandato presidencial a cuatro años, la autonomía del Consejo de Ministros, el establecimiento de la descentralización del país y la eliminación de los fueros eclesiásticos y militares llevaron a que se desencadene una ola de críticas de los sectores tradicionales y conservadores del país.

La prensa se convirtió en el escenario de estas confrontaciones, en las que cada parte defendía sus intereses. El momento de mayor crisis tuvo lugar cuando se promulgó la Constitución de 1856: se alzaron voces de protesta que culminaron con el alzamiento del general Vivanco en Arequipa. Dicha rebelión reflejaba el descontento de diversos sectores y regiones del país. Incluso el gobierno del general Castilla señalaba las deficiencias que tenía la Constitución de 1856. Estas circunstancias tornaron tensas las relaciones entre el poder ejecutivo y el legislativo. Las constantes críticas que recibió 
la Convención Nacional, acusada de querer perpetuarse en el poder para perjudicar al gobierno de Castilla, fue aprovechada por una facción del ejército, liderada por el coronel Pablo Arguedas, que procedió a dar un golpe militar y cerrar el Congreso. El gobierno de Castilla sacó ventaja de esta situación para revisar la Constitución de 1856; para ello, reunió al Congreso ordinario de 1858. A raíz de la convocatoria al nuevo Congreso, proliferaron los escritos que presionaban por la reforma constitucional. Esto no se pudo llevar a cabo en 1858, por la intensa critica del Congreso a Castilla y su gobierno, y se tuvo que esperar hasta 1860, cuando un nuevo Congreso se encargó de elaborar la nueva Constitución.

La caída de la Convención Nacional de 1855 y la suspensión de la Constitución de 1856 fueron el inicio de una serie de acciones que solicitaban la reforma total de la Carta Magna. Se acusaba que los transtornos que habían azotado la institucionalidad y el orden del país eran causados por seguir la influencia de ideas extranjeras nocivas, ideas que no podían ser aplicadas a nuestra realidad.

\section{La necesidad de reformar la Constitución de 1856}

Una serie de escritos conservadores denunciaron que la influencia de la escuela francesa había sido negativa para las naciones sudamericanas, porque las ideas radicales de la Revolución francesa habían sido la causa del caos del país. La nación, decían, debía seguir por el camino ya establecido desde los inicios de la república: practicar el sistema representativo. Además, el orden llegaría de la mano de hombres capaces y racionales que darían satisfacción a las demandas de la nación. Era el pensamiento de la modernidad tradicionalista que se estaba impulsando en la nación; el orden y el republicanismo nos Ilevarían a una nueva era. Estos hombres, que regirían los destinos del país, debían ser personas con aptitudes, capacidades y habilidades superiores, lo que les permitiría ejercer las funciones que el Estado requiriera. Ellos tendrían el derecho de gobernar el país bajo el principio de la soberanía de la inteligencia que el obispo Bartolomé Herrera venia impulsando desde la década de 1840, y que, a finales de la década de 1850, había resurgido, promovido por los sectores conservadores. Era un proyecto político que finalmente representaba a la élite de Lima: creían que, finalmente, ellos, la nueva élite surgida del guano, impondrían las leyes para todos los sectores sociales que no estaban alumbrados por la razón del conocimiento.

En las publicaciones que circularon durante los años 1858 y 1860, se recomendaba que los hombres incapaces fueran apartados del gobierno representativo. ¿Quiénes eran estos hombres incapaces? Según el pensamiento conservador, eran aquellos individuos con idealismos utópicos que, en su afán de buscar reformas no acordes con la situación del país, lo habían llevado por los senderos peligrosos del caos y el fracaso. Por esa razón debían ser apartados. Esa situación no debía repetirse. Claro está que se referían a los diputados liberales de la Convención de 1855, quienes, con el fin de establecer cambios significativos, habían creado la Constitución de 1856, que se denunciaba como el emblema del caos que se vivía en el país. Por ello, se planteó que el camino que debía guiarnos en la construcción del nuevo orden era analizar la realidad, ya que, de esta manera, se articularía una verdadera estructura de gobierno, acorde con las verdaderas necesidades del país (El sistema representativo, 1860, pp. 20-21).

Entre las críticas que se plantearon contra la Constitución de 1856, se destacaba que esta no había sido debidamente planificada y que se había estrellado con la realidad nacional, pues pretendía imponer el liberalismo mediante decretos. Este idealismo liberal, que deseaba imponer un orden social con individuos iguales en sus derechos políticos, fue muy criticado, pues había sectores de la población que eran considerados "incapaces naturales". Un hecho que causó gran revuelo en la élite limeña fue que los 
negros participaran en el proceso electoral de 1855 , cuando se eligieron a los diputados de la Convención Nacional.

El discurso que se utilizó para criticar las incongruencias de la Constitución corresponde a un marcado conservadurismo. Por ello, los sectores tradicionales de la sociedad decidieron no acatar la Constitución; la Iglesia, que fue uno de ellos, asumió un papel crítico a la norma constitucional. Esta circunstancia fue gestando una situación revolucionaria, pues la Iglesia, desde el periódico El Católico, asumió una postura confrontacional que llegó a su clímax cuando fue jurada la Constitución de 1856. Se denunciaba que los políticos liberales querían imponer sus creencias, además de manipular a la opinión pública en su favor.

Numerosas publicaciones se dieron a conocer entre los años 1858 y 1860. Muchas de ellas insistieron en que no había razón para acatar la Constitución liberal. Decían que si dicha Constitución se ponía en práctica, el edificio social del país se vería seriamente afectado por sus artículos, ya que se encargarían de demoler las instituciones representativas del país. El argumento de los escritos conservadores señalaba que las leyes debían llevarnos al sendero de la civilización, apartarnos del camino de la barbarie. En cuanto a las poblaciones, no se les debía dar derechos que no supieran utilizar; lo que las normas constitucionales debían hacer era apuntar a educar a sus respectivas sociedades:

Careciendo de educación republicana, hemos abrazado las ideas más estremas de la democracia, lanzándonos a un mar endeble, sin brújula, ni piloto; no tenemos las virtudes cívicas que se alimentan solo con la civilización de la mayoría, y hay en nuestra sociedad multitud de intereses encontrados. (Anónimo, 1860, pp. 4-5)

Esta realidad política del país permitirá preguntarnos cuál fue el papel que desempeñó el Gobierno ante las incongruencias de la Convención Nacional de 1855 y la Constitución de 1856. Hacernos esta pregunta es clave porque es conocido que se habían producido numerosos desencuentros entre ambos poderes del Estado. Se acusaba que los liberales deseaban superponer el poder del legislativo sobre el ejecutivo. Esta situación daba pie a denunciar que la Constitución era negligente con la realidad del país, pero también se debe precisar que la responsabilidad recaía sobre el poder ejecutivo, ya que este no había cumplido su labor de poner límites a la Convención Nacional de 1855 y a los "excesos" de los liberales. Así, el gobierno de Castilla y la asamblea liberal marchaban por caminos opuestos, ya que no se consultaban ni dialogaban. En esta situación se había desencadenado la crisis política: cada uno de los poderes del Estado obraba aisladamente, seguían sus respectivas ambiciones. De ahí que se llegó a tener como resultado un pésimo régimen constitucional.

Entre las acusaciones que se presentaron contra la Constitución de 1856, una de las más recurrentes fue que fomentaba la perversión del orden social. Esto se debió a que varios de los artículos de la Constitución eran señalados por ir contra las buenas costumbres y hábitos del país; demás, se decía que había un evidente deseo de favorecer a las masas que no se encontraban ilustradas, y que era poco saludable pretender que estas participaran en la vida política. Por otro lado, se acusaba que estas normas estaban corroyendo las instituciones más representativas del país: por ejemplo, las fuerzas armadas, que veían afectadas su moral y su disciplina, y también la Iglesia, que denunciaba que veía limitado su accionar por obra de la Constitución, al ser privados de sus fueros y otras prerrogativas. Todo esto ocasionó fuertes críticas. Hay que recordar que la Convención de 1855 entabló una discusión sobre la posibilidad de establecer la tolerancia religiosa en el país. Esta circunstancia fue muy atacada por los sectores conservadores. Otras medidas que se atacaron duramente son el restablecimiento de las juntas departamentales, el establecimiento del sufragio directo y la abolición de la pena de muerte. Las publicaciones conservadoras señalaban que esto se debía a que los liberales se dejaban llevar por su "desquiciamiento y desorden"1. Se trató de publicaciones tendenciosas que buscaban el respaldo de la opinión pública urbana para seguir presionando y hacer posible la implementación de una nueva Constitución.

Desde las primeras constituciones, al menos en la teoría, lo que frecuentemente se ha impulsado es el respeto de los derechos civiles y políticos, de la opinión y de la propiedad. Asimismo, en todas ellas se encuentran establecidos el principio de la separación de poderes, el derecho de igualdad ante la ley y la libertad de prensa. Pero la praxis nos señala que lo recurrente en la historia republicana es el incumplimiento de las normas constitucionales y legales. Esto ha sido uno de los grandes dramas del país, ya que ese incumplimiento de las leyes nos ha llevado a una constante inestabilidad política. La única Constitución que tuvo varios años de vigencia durante la primera mitad del siglo XIX fue la de 1839, que no estaba plagada de ideales liberales, sino de la tradición conservadora. Por ello, decían, debía seguirse ese sendero.

El único camino que quedaba para salir de aquella encrucijada, decían, era implementar la reforma de la Constitución. Para tal fin, lo que debía hacerse era rescatar las normas positivas que contribuían al desarrollo del país. La reforma constitucional debía plantearse como la erradicación de los artículos considerados innecesarios e irracionales y para los cuales la mayoría de los peruanos no se encontraba preparada. Lo único que se lograría con esas normas, aseguraban, era alterar los buenos hábitos de nuestros

1 Los liberales eran un grupo político que no necesariamente estaba homogenizado en sus ideales; el sector más confrontacional, del cual se denuncia excesos, es el de los denominados "radicales". 
ciudadanos. Lo que había que hacer era consolidar lo ya existente: por ejemplo, afianzar la idea de la libertad, sin la cual no se podría construir la ciudadanía.

El orden es otra figura anhelada por las diferentes publicaciones, pero conseguirla no era fácil, ya que era necesario tener autoridades con el suficiente poder para que puedan imponerse en todo el territorio. Esta situación no se daba con la Constitución de 1856, según se denunciaba, ya que le había arrebatado la capacidad de poder a la presidencia. Por ello, se recalcaba que nuestras autoridades no debían sufrir el despojo de su poder, pues ellos eran los responsables del mantenimiento del orden. Sin tal figura, el país caería nuevamente en el reino de la anarquía. La clase política de mediados del siglo XIX estaba obsesionada con acabar con la anarquía del país, pues lo único que se había tenido era una constante ingobernabilidad que había impedido la construcción de un Estado eficiente. Según los conservadores, había que prescindir de esas innovadoras ideas liberales, ya que solo nos habían conducido el despotismo y la anarquía (Proyecto de reforma de la Constitución sancionada en el año 1856, 1860, pp. 2-3).

La Constitución de 1856 expiró por la ceguera política de los liberales. Se hizo impopular ante los numerosos actores políticos tradicionales de la época: la Iglesia, el Ejército, el poder ejecutivo, la burocracia, el poder judicial. En esa crítica, se recalca a la Convención Nacional de 1855, una asamblea constituyente y legislativa dominada por los liberales, que fue acusada de ser foco de constantes conflictos, y que, además, le restó legitimidad al gobierno de Castilla. Por ello, se entiende el apoyo tácito de Castilla al golpe de 1857. Aprovechando aquella ruptura del orden constitucional, el Gobierno convocó a una nueva asamblea, con la finalidad de reformar la Constitución. Así, se reunió el Congreso extraordinario de 1858. Sin embargo, en vez de ejecutar la reforma, lo que se desarrolló fue un encarnizado enfrentamiento entre las facciones liberales y conservadoras que conllevó la casi paralización de las acciones del gobierno de Castilla.

La guerra civil de 1856 y sus trágicas consecuencias para los liberales habían demostrado que la amenaza del militarismo seguía tan vigente como desde la época de la independencia. Por ello, había que buscar contener los excesos de aquellos jefes militares ambiciosos de poder. La Constitución de 1856 lo había intentado, pero acabó siendo derogada. La inexperiencia de los legisladores había contribuido también a ese infeliz desenlace, pues, en su intento por regenerar el país, implementaron normas que fueron severamente criticadas. Estos desencantos no eran novedosos, venían desde la etapa de la independencia. La situación no había cambiado. La nueva reforma constitucional que se iba a desarrollar en 1858 vino precedida de una gran cantidad de escritos que planteaban hacer una tabula rasa con la Constitución de 1856. A pesar de ello, reapareció una prensa liberal, como El Constitucional (1858), que buscaba mantener los logros de la Constitución 0, al menos, rescatar los artículos destacables.

La reforma de la Constitución de 1856 ya había sido prevista por los convencionales de 1855, pues se había insertado en aquella Carta Magna un artículo dedicado a su reforma: el artículo 134 establecía que, para reformar uno o más artículos, se necesitaba que el proyecto sea aprobado en tres legislaturas ordinarias distintas. Lo que se buscaba era discutir convenientemente los cambios a implementar. Para muchos entendidos, el hecho de que se celebraran tres legislaturas ordinarias implicaba mucho tiempo, pues se necesitarían tres años para poder cambiar los artículos más controvertidos de la Constitución. Esta situación era nominal, según se denunciaba, pues habría sido difícil cumplirla.
Así se volvía a la tradicional frase "se obedece, pero no se cumple" (Proyecto de reforma de la Constitución sancionada en el año 1856, 1860, p. 49).

Antelas objeciones, por un lado, estaban quienes planteaban que solo se debían revisar partes de la Constitución; por otro lado, estaban quienes reclamaban que debería revisarse en su totalidad, ya que dicha Carta Magna estaba manchada con sangre de la guerra civil2 ${ }^{2}$. La situación en la República seguía siendo tensa por las consecuencias de aquel conflicto, por lo que el nuevo Congreso extraordinario de 1858 iba a tener una delicada misión: normar en beneficio de la población y satisfacer las diferentes posturas políticas, para no ser acusado de violentar las leyes del país.

\section{Puntos críticos de la Constitución de 1856}

Uno de los temas sensibles entre los sectores liberales y conservadores fue la discusión respecto de la pena de muerte, ya que esta afectaba los derechos individuales. Los liberales lo habían planteado y lograron establecer su abolición en la Constitución de 1856. Con la publicación del escrito Opúsculo sobre la necesidad de reformar la Carta Fundamental de la República (1860) volvió la crítica sobre tal cuestión. La publicación hizo una cerrada defensa sobre las bondades de la pena de muerte. Según creían, contenía a los individuos que deseaban infringir las leyes y a los asesinos. Decían que, de no existir esta sanción, las prisiones habrían estado llenas de infractores de la ley; por tanto, esta norma era una garantía que evitaba que aumentaran los delitos en el país. La publicación reclamaba que la abolición de la pena capital iba a desencadenar problemas, pues

2 Una nueva guerra civil se desencadenó en 1856, cuando Arequipa se pronunció contra la promulgación de la Constitución. Se enarbolaron las banderas de la defensa de las tradiciones del país. Este conflicto se prolongó hasta 1858. 
solamente las naciones con un alto sentido de moral podían prescindir de tal medida; y ese, decían, no era nuestro caso. Lo que debía mantenerse era la proporcionalidad del delito con la pena, pues, de no darse, solo se sentarían malos precedentes para la justicia. Así, para ellos se hacía necesaria la reforma del artículo 16 de la Constitución (Opúsculo sobre la necesidad de reformar la Carta Fundamental de la República, 1860, p. 9).

Este debate se realizó en el Congreso extraordinario de 1858 y en el Congreso de 1860. Años después, en 1862, Francisco de Paula González Vigil publicó Opúsculo sobre la pena de muerte, en el que volvió a la carga sobre el por qué debía abolirse la pena de muerte, ya que él asociaba esta norma con la idea del progreso de las naciones modernas. Este planteamiento liberal, de tendencia progresista para el siglo xIx, fue desechado, ya que la mentalidad y las costumbres de la época lo señalaban como una medida peligrosa para la estabilidad social.

Otro de los puntos que se criticaba de la Constitución del 56 era el referido a la movilidad de los empleos. Se planteaba que, a pesar de que se había proclamado la abolición de la inamovilidad de los empleos - que era presentada como el triunfo de la modernidad y de la justicia, pues los empleos ya no serían propiedad del empleado ni de sus familias-, el detalle estaba en que, según los escritos tradicionalistas, había sectores del Estado que sí necesitaban empleos fijos. Por ejemplo, en los sectores judiciales y en el manejo de rentas, pues allí podría ocurrir una serie de inconvenientes: el Gobierno de turno podría colocar en esos cargos a funcionarios de su agrado, adictos a su causa, pero sin aptitudes para tales puestos. Por tanto, la ansiada movilidad no produciría los efectos deseados por la ley, en tanto lo único que dejaría serían instituciones que perderían credibilidad y eficacia. Para evitar estos inconvenientes, decían, los empleados del sector judicial y de la hacienda pública deberían mantenerse en sus cargos, pues tenían el conocimiento de sus respectivos sectores. Lo que debía buscarse era el perfeccionamiento de sus oficios. De esta manera, se conseguiría mejorar su labor y que fueran más eficaces. Todo lo contrario acontecería si es que se mantenía la movilidad de los cargos: Ios empleados no se sentirían seguros del esfuerzo que realizaban en el trabajo, pues, al desplazarlos de un lugar a otro, ocasionarían que su esfuerzo en el trabajo disminuyera y no se consiguiera la eficiencia que se solicitaba de dichos funcionarios. Pero las medidas de los liberales apuntaban a acabar con el mal denominado empleomanía, que lo único que había ocasionado era debilitar la gestión de las labores de los trabajadores. Por ello, urgía la reforma, para poder acabar con ese patrimonialismo que se había heredado de la época colonial.

La abolición de los fueros era otro de los puntos controversiales de la Constitución. Era apoyada por los liberales, quienes veían en la sola existencia de estos una parte del pasado colonial que buscaban desterrar, pues, para ellos, alcanzar la modernidad implicaba eliminar tal anacronismo. Aquí un comentario de la época, publicado en el Diccionario para el pueblo:

El fuero es un absurdo en república, puesto que nadie debe estar exento de las leyes que rigen a todos. Esos privilegios de castas y órdenes sociales son restos de las monarquías absolutas de la edad media que van despareciendo. (Espinosa, 1855, p. 427).

La abolición de los fueros eclesiásticos y militares fue criticada enérgicamente por la prensa conservadora. Uno de los sectores afectados fue el Ejército, institución de mucho arraigo en la vida política del país. La crítica señalaba que la aplicación de tal medida implicaba desnaturalizar el carácter de la milicia, reducirle su condición de orgullo, y que lo único que sucedería con la aplicación de tal medida era la pérdida de la disciplina y del orden dentro del ejército: sus integrantes estarían a merced de las maquinaciones de personas ambiciosas que podían llevar al país a vivir constantes desórdenes, y lo único que se conseguiría era prolongar el caos republicano con el apoyo de las Fuerzas Armadas (Opúsculo sobre la necesidad de reformar la Carta Fundamental de la República, 1860, pp. 8-9). Es de notar que, por aquellos años, había una fuerte corriente que buscaba subordinar las Fuerzas Armadas a los intereses civiles, y para ello había que acabar con la oligarquía militar. Diversas publicaciones en la prensa de la época, principalmente liberal, hicieron acotación de tal demanda.

La supresión del fuero eclesiástico ocasionó una generalizada resistencia. Las publicaciones de los sectores católicos llegaron a mencionar que dicha medida había sido criticada por la población, pues señalaban que las normas constitucionales no debían contradecir el orden normal de las cosas. Este pensamiento seguía el orden propuesto por los conservadores, quienes argumentaban que era necesario respetar lo conseguido y no violentarlo de la manera en que lo hizo la Convención liberal de 1855. Los órganos de prensa allegados a los sectores eclesiásticos, como El Católico y El Progreso Católico, siguieron sus reclamos con un discurso confrontacional:

Por desgracia no faltan aún cerebros calenturientos, que fiándose demasiado de sus propias lucubraciones y renegando de la historia, todavía forcejean por hacer entrar a los pueblos en el laberinto sin salida de un estrafalario y ridículo utopismo ${ }^{3}$.

Como se puede apreciar, los sectores conservadores mantenían la idea de que el progreso o cualquier tipo de innovación era un mal que ocasionaba daños a la nación. Posteriormente, cuando el Congreso de 1860 ratificó

3 El Progreso Católico, 1860. Diario de corte conservador promovido por los sectores afines a la Iglesia católica. En su primer número, del 14 de julio de 1860, publica un artículo que lleva por título "Prospecto", en el que expresa su manifiesto contra las amenazas a la sociedad peruana. 
la abolición de los fueros, los ataques prosiguieron hasta llegar a tildar al Congreso de engreído y de buscar romper el pacto entre la Iglesia y el Estado. A pesar de todas las críticas conservadoras, el sentido de construcción del Estado triunfó, ya que se logró consolidar el pensamiento secular en contra de los sectores tradicionalistas.

La descentralización era otra de las políticas que buscaban establecer los liberales. Para ello, la Constitución de 1856 había ordenado el restablecimiento de las juntas departamentales. Estas eran instituciones criticadas por los sectores tradicionales, a pesar de que podían tener algo de favorable, pues se argumentaba, nuevamente, que podían llevarnos al desorden. El camino que había conducido al establecimiento de las juntas era la búsqueda del equilibrio entre los distintos departamentos y las autoridades de la república. En teoría, se Ilegaría al ansiado equilibrio de poderes, que, de paso, ayudaría a establecer asambleas locales que facilitarían la gestión del Gobierno. Esto se desarrollaría siempre y cuando se tuviesen las condiciones favorables. El camino a la descentralización se estaba abriendo con estas medidas. Sin embargo, los conservadores señalaban que este tipo de medidas ya se habían intentado establecer en las constituciones anteriores y habían tenido un desenlace no muy feliz. Por ello, seguían señalando que el centralismo era necesario para tener un gobierno eficaz, ya que permitía al gobernante de turno tener influencia en las provincias y desarrollar un gobierno más efectivo; además, estaba el recuerdo de la Confederación Peruano-Boliviana, que había aplicado una política descentralista con un resultado nada grato, ya que se había atentado contra la soberanía e integridad nacional (Planas, 1998, p. 161).

De esa manera, la crítica contra las juntas departamentales se centró en que eran instituciones que habían servido para disputarle el poder al Gobierno central, por lo cual su restablecimiento, decían, conllevaría la ingobernabilidad del país. La situación de la nación se agravaría, pues se denunciaba que las constantes confrontaciones entre el Gobierno central y las provincias, que se reproducían en el Congreso, se desarrollarían en los departamentos, y, por ende, las relaciones se volverían conflictivas y llevarían a prolongar el caos y el atraso al interior del país. Erróneamente, se creía que allí no se disponía de personal adecuado para el desarrollo de la administración local, y cuando lo había, se dudaba de su solvencia moral para llevar a buen puerto las reformas.

Todas las críticas, finalmente, fueron escuchadas, ya que en la Constitución de 1860 no se mencionó nada sobre la descentralización de dichas juntas. Las funciones que se encargaban antes a la juntas fueron asumidas por los prefectos y subprefectos, que seguían siendo autoridades dependientes del ejecutivo. El impulso reformista de la descentralización fue finalmente suprimido y se impuso el centralismo presidencialista desde Lima. Las provincias tuvieron que esperar décadas para poder revertir esta medida. Esto es una constante en la política latinoamericana: la lucha de proyectos centralistas y federales tendrá repercusiones en las diferentes constituciones de Hispanoamérica. Nuestros liberales y conservadores siguen esa tendencia.

Siguiendo la crítica al modelo descentralista, la situación de las municipalidades era otro de los puntos que se planteaban para la reforma. La denuncia que se lanzó contra la Convención liberal fue que las municipalidades no habían sido fortalecidas ni potenciadas por la Constitución de 1856. Lo que se tenía era un panorama crítico: las municipalidades eran acusadas de ser un obstáculo para el Gobierno central, ya que podían oponerse al centralismo autoritario; por ello, los prefectos y subprefectos designados habían asfixiado cualquier intento de desarrollar un gobierno local, con el fin de limitar sus alcances. De allí que las denuncias que se lanzaron contra las municipalidades buscaron demos- trar su inviabilidad. Así, se dijo que en las capitales departamentales se desarrollaba una situación caótica: había demasiados inconvenientes que permitían apreciar la insignificancia de dicha institución. Las personas a cargo de los gobiernos locales no eran las más idóneas para desempeñar sus labores, ya que se preocupaban por entablar debates intrascendentes que no solucionaban los problemas directos de las ciudades. Un indicativo de esta crisis municipal era el hecho de haber abandonado la ornamentación de las urbes que dirigían. Se señaló que había una carencia del alumbrado en las calles, que los mercados habían sido prácticamente abandonados y estaban expuestos a la inseguridad. En cuanto a la situación económica, se decía que las autoridades no realizaban un control a los precios de los alimentos, lo fue aprovechado por los vendedores. Toda esta situación caótica se debía a que los municipios no poseían rentas fijas, entonces se veían notoriamente limitados al no poder atender las demandas y necesidades de sus respectivas ciudades (Anónimo, 1860, p. 13).

Si lo descrito anteriormente ocurría en las municipalidades de la capital de los departamentos, la situación era más caótica en las capitales provinciales y locales, que, se decía, no merecían ostentar el título de municipalidades por las severas carencias que las aquejaban. A esta situación hay que añadir que las relaciones que se desarrollaban entre las municipalidades y los representantes del Poder Ejecutivo (los prefectos y subprefectos) eran difíciles y conllevaban un constante desorden en la vida política. Por ello, las criticas conservadoras, favorables al mantenimiento del centralismo, acusaron que las municipalidades eran cuerpos políticos sumidos en una completa decadencia, sin una dirección adecuada; por ende, era aconsejable, al igual que con las juntas departamentales, solicitar su desaparición, puesto que sin ellas la vida pública del país sería más llevadera. Todos estos cuestionamientos finalmente tuvieron eco en 
la Constitución de 1860, y las municipalidades sufrieron una serie de cambios que se plasmaron en el artículo 118, el cual establecía lo siguiente: "habrá municipalidades en los lugares donde designe la ley; la cual determinara sus funciones, responsabilidad, calidades de sus miembros y el modo de elegirlos". Esto nos indica claramente que los gobiernos municipales vieron disminuidos sus márgenes de acción y quedaron expuestos a la influencia de los distintos gobiernos de turno.

Otra seria crítica que se estableció contra la Constitución de 1856 fue dirigida contra la organización del Congreso, que se recomendaba que sea bicameral, pues este sistema había llevado a diversos países al orden esperado. Los escritos que circulaban en los espacios públicos exclamaban que era necesario precisar la reorganización del Congreso porque ello garantizaría el orden, a la vez que otorgaría madurez a la hora de reflexionar y realizar las leyes. Desde este punto de vista, el gran fallo de la Constitución del 56 radica en que no especificaba de una manera clara cómo se implementaría la bicameralidad; de allí que las críticas conservadoras señalasen que no había una forma clara para elegir a las personas que se presentaban a la Cámara de Senadores. En tal situación, se reiteró que al Parlamento debían ingresar personas ligadas a la carrera pública. De no hacerse así, ingresarían al Congreso personas sin experiencia y se complicarían las gestiones parlamentarias, lo que propiciaría la corrupción del Congreso (Breves reflexiones acerca de la organización del poder legislativo, 1860, pp. 24-30).

Se necesitaba que el legislativo fuera un poder independiente, eficaz, que condujera al país hacia el progreso. Para ello se debían garantizar leyes aceptables para la ciudadanía ${ }^{4}$, tal como era el caso de los Congresos británico y norteamericano. Para cumplir tal meta, había que hacer una adecuada selección de representantes; de ahí que fuera imperativo tener una Cámara de Diputados que representara a los pueblos de la república; ellos se encargarían de hacer las normas legales. Las leyes producidas por la Cámara de Diputados necesitarían ser monitoreadas y corregidas por otro cuerpo legislativo. Por eso se precisaba la existencia de una Cámara de Senadores, que tendría a su cargo una medida fundamental: la reflexión de las leyes. Como los senadores debían ser personas idóneas para el desempeño de tal cargo, se debía pedir más requisitos para desempeñarlo, debía establecerse tener una mayor edad, en promedio, que la de diputados. Según la Constitución de 1856, solo se necesitaba cumplir 25 años de edad para poder desempeñarse en ambos cargos. La cuestión de la edad era vista como la experiencia que otorga sabiduría, planteamiento tradicional que se vio reforzado por lo acontecido con Salaverry en la Confederación Peruano-Boliviana, cuando su juventud nos llevó al desastre ante Santa Cruz.

Por lo tanto, la elección de los senadores se convirtió en un punto crucial para la gobernabilidad del país; su elección no podía ser dejada a la suerte, y esto era para ambas cámaras. Las críticas hacia los liberales era que se permitía que la Constitución del 56 dejara al azar la elección de los senadores y diputados. Las consecuencias de esta falla, decían, serían fatales, pues se lograría tener pésimos representantes parlamentarios. En tal sentido, se reiteró que para elegir representantes de calidad para el Senado era necesario exigir más requisitos. El proceso eleccionario para el Senado debía ser distinto al de diputados, ya que así se conseguiría tener un cuerpo legislativo más competente y capacitado para implementar medidas pertinentes a la realidad del país; debía dejarse de lado aquel idealismo liberal que solo había traído conflictos.

Otra denuncia contra la Constitución se dio en referencia a la situación de los extranjeros y peruanos naturalizados, los cuales no podían ejercer cargos o trabajar para el bienestar del país. Solo podían hacerlo al cumplir 20 años de residencia 0 ejecer la misma cantidad de tiempo en alguna profesión. Esta situación no se desarrolló en otros países de la región, que sí aprovecharon las capacidades de los extranjeros. En consecuencia, se planteó que la calidad del peruano no la debía determinar el hecho de haber nacido en territorio nacional. Para poder insertar a los extranjeros más destacados, que podían contribuir al desarrollo del país, se hizo necesario cambiar la norma constitucional. Lo que se tenía con la Carta Magna de 1856 era de una absoluta mezquindad con los extranjeros (Opúsculo sobre la necesidad de cambiar la Constitución, 1856, pp. 16-17). El aprovechamiento de la población extranjera era parte de este proyecto de modernización tradicionalista, en el que se buscaba integrar europeos con el objetivo de revitalizar la república. Familias extranjeras provenientes de Europa lograron insertarse en las élites del país, pero lo cierto es que hubo diversidad de migrantes y que no todos fueron integrados a la sociedad republicana del siglo XIX, como sucedió con los chinos, una mayoría en este proceso migratorio.

Las publicaciones conservadoras que se difundieron entre 1858 y 1860 centraron las críticas en que la Constitución del 56 contenía normas que proyectaban sombras y nada de realidades, de allí que dijeran que era una "carta monstruo". Aseguraban que la Convención de 1855, dejándose llevar por el espíritu del radicalismo, había destruido los principios de autoridad y confundido las atribuciones de poder. En su deseo de imponer la modernidad liberal, la Constitución había establecido una serie de disposiciones que no iban con la realidad del Perú: era improbable que con ellas se alcanzara el camino del progreso. Los grupos afectados por la reforma constitucional se expresaron en términos muy duros sobre la Constitución del 56: sectores como el clero, la milicia, la magistratura, los empleados públicos,

4 En el Diccionario para el pueblo de Juan Espinoza se definía al Congreso como un cuerpo deliberativo encargado de dictar las leyes que la nación se da por medio de sus representantes. 
todos tenían suficientes motivos para perseverar en sus ataques. Por tal razón, era necesario, según apuntaban las críticas, reformar la Carta de 1856 para salvar la nación del caos que se avecinaba (Breves reflexiones sobre el punto de capital que debe abrasar la reforma constitucional, 1860, pp. 1-5).

\section{Conclusiones}

La reforma constitucional que se pedía para la Constitución de 1856 era impostergable. La sublevación de Vivanco en Arequipa y el alzamiento generalizado de las provincias en 1857, a pesar de sofocarse la rebelión, eran un motivo para señalar que aquellas insurrecciones se habían debido a que las provincias rechazaban la Constitución y algunos de sus controversiales artícu-
Ios. Una serie de publicaciones, que aparecieron entre 1858 y 1860, solicitaban la necesidad de la reforma de la Constitución de 1856. Los sectores que presionaban para ejecutar los cambios eran los conservadores, quienes, apegados a la racionalidad tradicionalista, argumentaban que el desorden y el caos eran consecuencia de estas reformas radicales de los liberales, y que, por tanto, era imperioso derogar la Constitución y elaborar una nueva. Algo que hay que destacar es que las publicaciones conservadoras no registraban la autoría del escrito, sino que se daban bajo la figura del anonimato.

Según el punto de vista conservador, los puntos a reformar en la Constitución se dirigían a lograr la reorganización del Estado. Los ejes de la reforma eran el reforzamiento de la autoridad presidencial; la bicamera- lidad del legislativo, para mejorar la racionalidad de las leyes y contar con personas adecuadas para desempeñar estas labores (claro está, bajo la lógica de la "soberanía de la razón"); el rechazo de la descentralización del país, por considerar que no había suficiente personal que guíe los destinos de los pueblos al interior del territorio nacional; la abolición de los fueros, tanto eclesiásticos como militares, que fue severamente criticada, siguiendo el clásico argumento de que solo personas competentes podían juzgarlos.

Para finalizar, lo que se aprecia en los pedidos de la reforma constitucional es que apuntaban a consolidar el modelo republicano, sea liberal 0 conservador. Lo que se buscaba era establecer un legado que permitiera tomar medidas que posibilitaran la viabilidad del país, bajo el ideal de la modernidad tradicionalista.

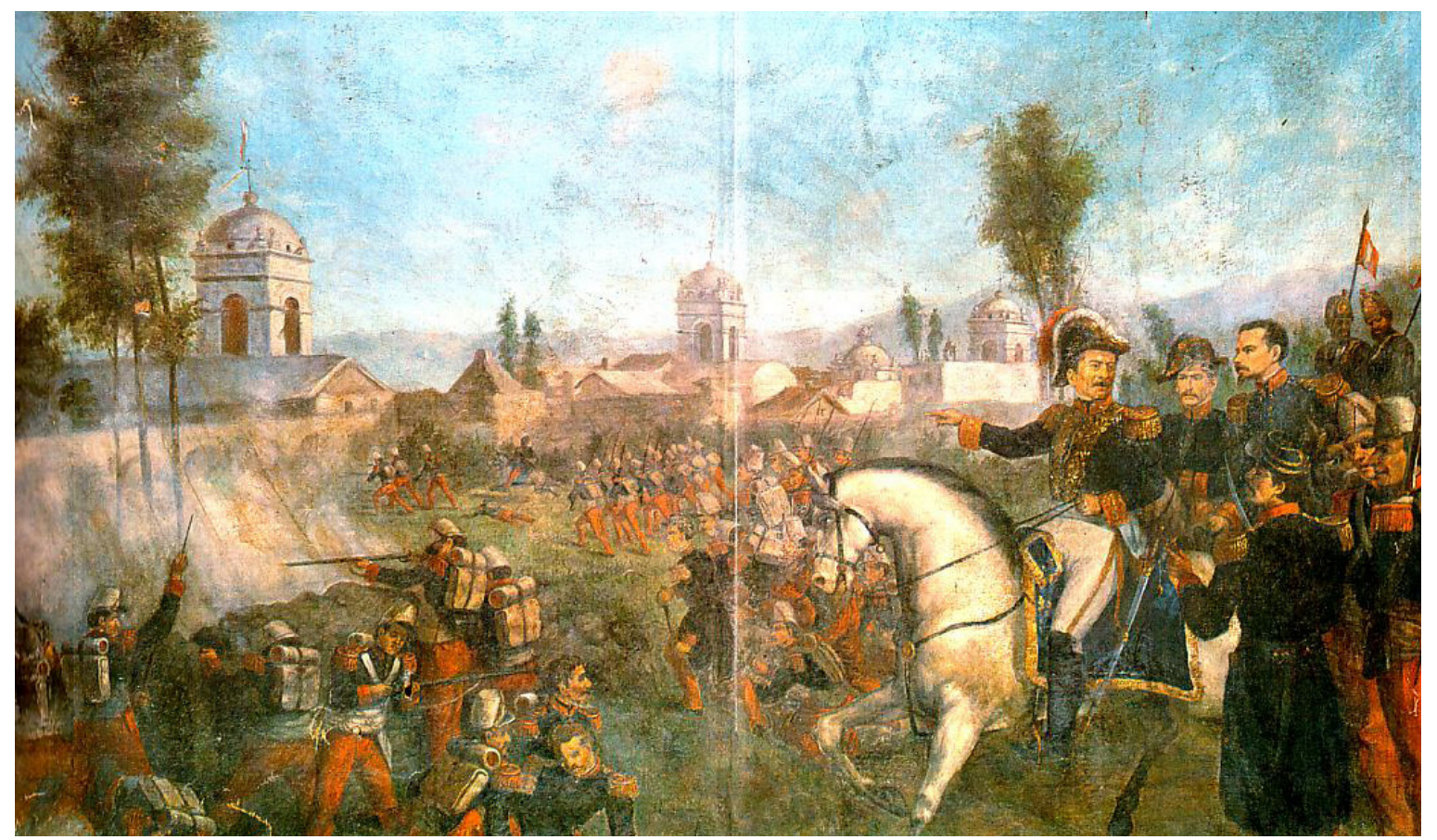

Óleo sobre la toma final de Arequipa el 7 de marzo de 1858. Autor anónimo (circa 1860). Museo Nacionald de Arqueología, Antropología e Historia. 


\section{Blibliografía}

Benvenuto, N. (1926). Crónicas parlamentarias del Perú, 1855-1859. Lima: Imprenta Americana Plazuela del Teatro.

Breves reflexiones sobre el punto capital que debe abrazar la reforma de la Constitución de 1856. (1860). Tacna: Imprenta de Andrés Freire.

De Trazegnies, F. (1992). La idea del Derecho en el Perú republicano del siglo xix (2.a edición). Lima: Fondo Editorial de la PUCP.

Del ÁgulLA, A. (2013). La ciudadanía corporativa. Política, constituciones y sufragio en el Perú (1821-1896). Lima: IEP.

El sistema representativo y la cuestión del día. (1860). Lima: Establecimiento Tipográfico de Aurelio Alfaro.

Espinosa de los Monteros y Lanza, J. (1855). Diccionario para el pueblo. Lima: Imprenta Libre.

Gálvez, J. (1858). La Convención Nacional y la Constitución de 1856. Lima: Imprenta de José Félix Moreno.

González VIGIL, F. (1862). Opúsculo sobre la pena de muerte. Lima: Tipografía Nacional por Manuel de Cortés.

HerRera, B. (1860). Proyecto de Reforma Constitucional. Lima: Imprenta de José Masías.

Jamanca Vega, M. A. (2015). La Constitución inacabada. Ideas y modelos constitucionales en el momento fundacional del Perú. Primera mitad del siglo xix. Lima: Fondo Editorial de la UNMSM.

JiYaGón, J. C. (2007). "La Convención Nacional y la Constitución de 1856. El ataque conservador a los liberales". En Uku Pacha, (11), 119-124.

Las constituciones del Perú y la situación actual de esta República. (1860). Lima: Imprenta de José María Masías.

Observaciones sobre la Constitución de 1856. Necesidad de su reforma. (1858). Lima: Imprenta de Manuel Langori.

Opúsculo sobre la necesidad de reformar la Carta Fundamental de la Republica, dada por la Convención Nacional. (1860). Cusco: Imprenta republicana por Mariano Campos.

Planas, P. (1998). La descentralización en el Perú republicano (1821-1998). Lima: Municipalidad Metropolitana de Lima.

SobrevilLa, N. (2004). "El proyecto liberal y la Convención Nacional de 1855". En C. Mc Evoy (ed.), La experiencia burguesa en el Perú, 1840-1940 (pp. 223-243). Madrid: Iberoamericana/Vervuert.

SobrevilLA, N. (2005). "Conflicto regional, guano y poder". En P. Drinot y L. Garofalo (eds.), Más allá de la dominación y la resistencia. Estudios de historia peruana, siglos XVI-XX (pp. 181-214). Lima: IEP.

SobreviLLA, N. (2009). Batallas por la legitimidad: Constitucionalismo y conflicto político en el Perú del siglo xix (18121860). Revista de Indias, LXIX(246), 101-128. 